\title{
Biodiversity of endophytic fungi from Mukia maderespatana (L) M. Roem - a first report
}

\begin{abstract}
Endophytic fungi are eukaryotic organisms that live inside plant tissues with symbiotic association and they have been recognized as a valuable source of novel bioactive metabolites, antibiotics, anti-cancerous compounds, antioxidants, enzymes, vitamins, texturizing agents and pigments. In the present investigation endophytic fungi were isolated from Mukia maderespatana (L) M. Roem from Western Ghats of Sathyamangalam region for the first time. The collected samples were taken to the laboratory under aseptic condition they were sliced of in to Leaf, Stem, and Root segments, surface sterilized and inoculated in PDA plates for isolation of endophytes. Biodiversity of endophytic fungi in various segments of the plant were determined by statistical analysis which includes colonization frequency, Relative density of colonization, EIR, Shannon Index, Gleason Index.
\end{abstract}

Keywords: endophytic fungi, shannon index, gleason index
Volume 4 Issue 4 - 2017

\author{
Kannan KP,Thilakavathi R, Madhan Kumar D, \\ Senthamarai M \\ Department of Biotechnology, Bannari Amman Institute of \\ Technology, India
}

Correspondence: Kannan KP,Assistant Professor (Selection Grade), Department of Biotechnology, Bannari Amman Institute of Technology, Sathyamangalam, Erode District, Tamil Nadu, India, Email drkpkannan@gmail.com

Received: January 26, 2017 | Published: April 17, 2017

\section{Introduction}

Endophytic fungi produce various secondary metabolites such as enzymes, antitumor substances, antimicrobial substances, pigments and plant growth hormones and have wide variety of applications in pharmaceutical, textile, painting and food industrial processes. ${ }^{1}$ Colors provide attracting appearance to marketable products such as food products, textiles, and pharmaceutical products. There are many artificial synthetic colorants, which have widely been used in foodstuff, dyestuff, cosmetic and pharmaceutical manufacturing processes, comprise various hazardous effects. The aesthetic and sensorial values of the food we eat is indicated by the colour, that is also indices of the freshness and safety of the food. ${ }^{2}$ Thus, the food colorants are used as additives in the food industry which becomes a significant factor for both food manufacturers and consumers for determining the acceptability of processed food. There are many limitations of synthetic pigments. The precursors, used in the production process of synthetic pigment, have many carcinogenic hazardous effects on the workers. The wastes of the production process are also harmful. They are itself non-environment friendly and non-biodegradable. ${ }^{3}$ The present investigation endophytic fungi were isolated from Mukia maderasapatana (L) M. Roem for the first time.

\section{Materials and methods}

\section{Collection of plant materials}

The medicinal plant Mukia maderespatana (L) M. Roem were collected from Wester Ghats of Sathyamangalam region, Erode district, Tamil nadu, India in polythene bags (Figure 1) and processed within 24 hours. The stem, leaf and root segments from the collected plants were used for the isolation of endophytic fungi after surface sterilization.

\section{Surface sterilization of collected plant}

The collected plants were gently rinsed with running tap water to remove dust and debris. The leaves, stems and twigs were cut into segments (50 leaf segments, 50 root segments and 50 segments from stem) and the samples were disinfected with $75 \%$ ethanol for 1 minute.
Then the segments were immersed in $4 \%$ sodium hypochlorite for 45 seconds followed by immersing them in the $75 \%$ ethanol for 30 seconds. It was followed by rinsing the segments in sterile distilled water for three times to remove the surface sterilization reagents and dried by using blot dry paper. ${ }^{4}$

\section{Isolation of endophytic fungi}

The surface sterilized segments were placed in the petridish (10 segments in each plate) containing Potato dextrose agar medium supplemented with streptomycin for the suppression of the growth of bacteria. The plates were incubated at room temperature until the mycelium or colony appears on the plate. To preserve as a pure culture, the endophytic fungi was inoculated in PDA slant. The purified endophytic isolates were transferred separately to PDA slants and accessioned accordingly depending upon the plant and plant parts from which they have been isolated. Finally all the purified endophytes were maintained at $4^{\circ} \mathrm{C}$ till further used On basis of morphology of surface texture, pigmentation and spores at the hyphal tips which were used to identify the endophytic fungi. ${ }^{5}$

\section{Identification of the isolated fungi}

The fungal isolates were mounted on the sterile slides then it was stained with Lacto phenol cotton blue and then examined in 100X light microscopy. The identified fungal isolates from the respective plant tissue segments were then sub cultured in a petri dish which contains sterile PDA media. To preserve as a pure culture, the endophytic fungi was inoculated in PDA slant and stored at $4^{\circ} \mathrm{C} .{ }^{1,6}$

\section{Analysis of results}

\section{Colonization frequency}

The colonization frequency (CF \%) of each endophyte was calculated following the method by. ${ }^{?}$

$=$ Number of species isolatedNumber of segments screened $\times 100$

\section{Relative percentage of occurrence}

Relative Percentage Occurrence (RPO) of each group (viz., 
Ascomycetes, Hyphomycetes, Coelomycetes and Sterile forms) of fungal species in each plant species was calculated as follows.

sity of colonization of one groupTotal density of colonization $\times 100$

\section{Endophytic infection rate}

er of infected segmentsTotal number of segments screene $\times 100$ Endophytic infection rate was used to determine the percentage of infection by endophytes in each segment of plant. ${ }^{8}$

\section{Jaccard similarity co-efficient}

To describe the taxonomic affinity of endophytic fungi among the various parts of the plant, a Jaccard's coefficient $(\mathrm{J})$, was used to measure the similarity between pairs of samples. ${ }^{9}$

$$
J=a(b+c)-a
$$

Where a represents the number of species occurring in both samples, b represents the number of species restricted to sample 1 , and c represents the number of species restricted to sample 2. JI ranges from 0 (no taxa shared) to 1(all taxa shared).

\section{Biodiversity indices}

\begin{tabular}{|c|c|c|}
\hline A & Shannon Diversity Index: & $H S=-\Sigma j(p j \ln p j)$ \\
\hline B & Shannon Evenness: & $\mathrm{EH}=\mathrm{H} / \mathrm{Hmax}=\mathrm{H} \ln \mathrm{S}$ \\
\hline C & $\begin{array}{l}\text { Relative index for } \\
\text { Shannon: }\end{array}$ & $\mathrm{HSR}=\mathrm{H} S / \mathrm{H} \mathrm{Smax}=\mathrm{H} \mathrm{S} / \ln \mathrm{Ni}$ \\
\hline D & Gleason index: & $\mathrm{H} \mathrm{G}=\mathrm{N} p-\mathrm{I} / \mathrm{ln} \mathrm{N} \mathrm{i}$ \\
\hline$E$ & $\begin{array}{l}\text { Relative index for } \\
\text { Gleason: }\end{array}$ & $\begin{array}{l}\mathrm{H} \text { GR }=\mathrm{H} \text { G/H Gmax }=\mathrm{N} P-\mathrm{I} / \mathrm{N} \\
\mathrm{I}-\mathrm{I}\end{array}$ \\
\hline
\end{tabular}

Where Ni is the total number of individuals, $\mathrm{Np}$ is the number of species identified among these isolates, and $\mathrm{pj}$ is the proportion of individuals in the jth species, HGmax and HSmax are the greatest possible values of $\mathrm{HG}$ and $\mathrm{HS}$ in a sample of Ni individuals. These maximal values are reached for $\mathrm{Np}=\mathrm{Ni}$ (hence, $\mathrm{pj}=1 / \mathrm{Ni}$, for all $\mathrm{js}$ ), and equal $(\mathrm{Ni}-1) / \operatorname{lnNi}$ and $\ln \mathrm{Ni}$ respectively. ${ }^{9}$

\section{Results and discussion}

\section{Isolation of endophytic fungi}

About 150 segments of leaf, stem and root from the collected medicinal plant Mukia maderasapatana (L) M. Roem (Figure 1) were plated on Potato Dextrose Agar plates under aseptic conditions after surface sterilization for isolation of endophytic fungi (Figure 2).

\section{Identification of the isolated fungi}

The emerging fungal colonies from the sterilized segments were identified by lactophenol cotton blue staining and then subcultured in PDA plates and incubated at $28 \pm 2^{\circ} \mathrm{C}$ for $7-14$ days. For maintaining isolated pure cultures, they were inoculated in slants and stored at $4^{\circ} \mathrm{C}$ till use (Figure 3).

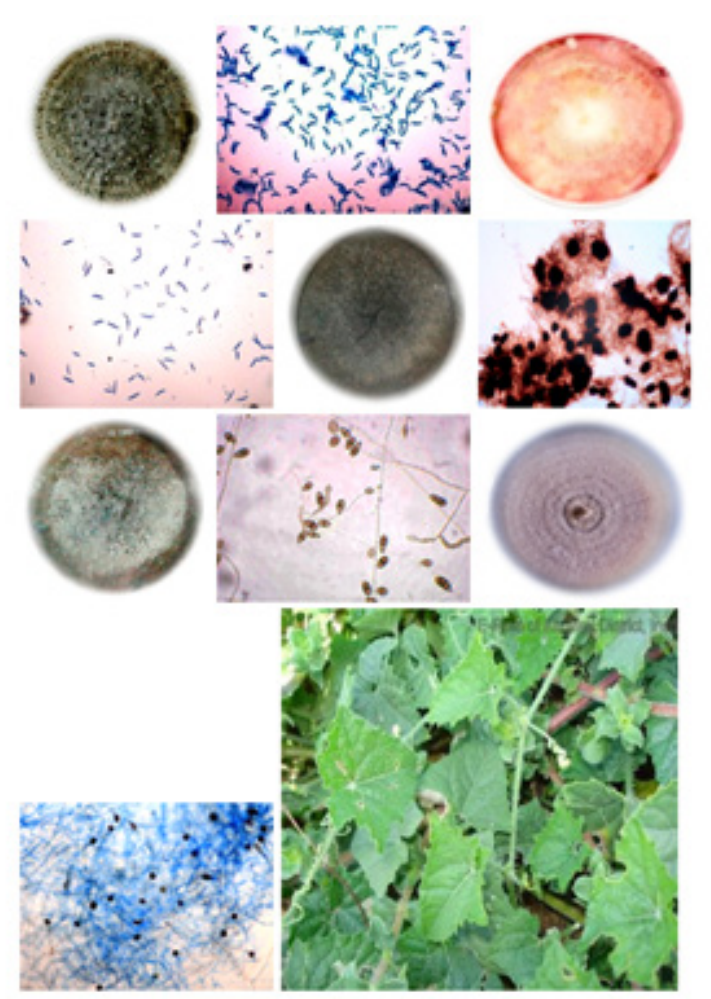

Figure I Habit of Mukia maderesapatana (L) M. Roem.

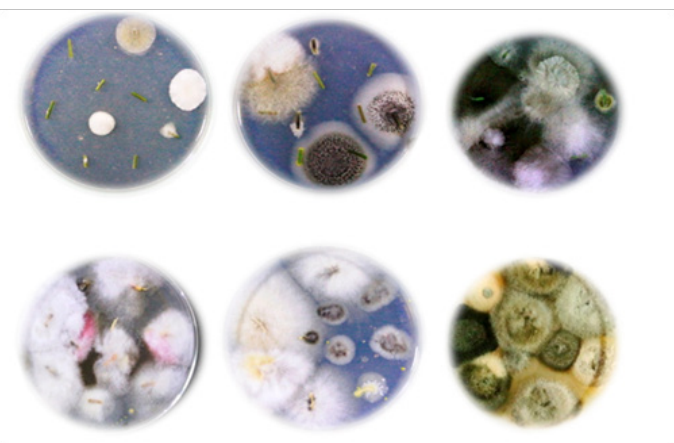

Figure 2 Endophytic fungal propagules emerging out from the sterilized tissues.
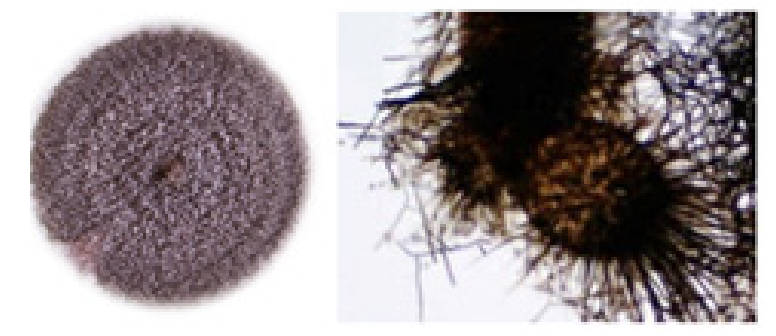

Figure 3 Pure culture and micrographic images of selected endophytic fungi reported from the medicinal plant. 


\section{Analysis of results}

Among 150 segments of leaf, stem and root screened from the medicinal plant Mukia maderasapatana (L) M. Roem 132 isolates of 12 species belonging to 9 genera were obtained. The remaining 3 nonsporulating fungal isolates were classified as sterile morph species (Table 1).

Table I List of endophytic fungi isolated from different segments of Mukia maderasapatana (L) M. Roem

\begin{tabular}{|c|c|c|c|c|}
\hline Sl. No & Name of the isolates & Leaf & Stem & Root \\
\hline \multicolumn{5}{|c|}{ Asomycetes } \\
\hline 1 & Chaetomium sp. & - & 5 & 6 \\
\hline 2 & Chaetomium spiralis & - & - & 2 \\
\hline \multicolumn{5}{|c|}{ Hyphomycetes } \\
\hline 3 & Nigrospora oryzae & 3 & - & - \\
\hline 4 & Nigrospora spherica & 16 & 4 & - \\
\hline 5 & Aspergillus niger & - & 7 & 10 \\
\hline 6 & Nigropora sacchari & 1 & 3 & - \\
\hline 7 & Trichoderma viridae & - & 1 & - \\
\hline 8 & Fusarium oxysporum & - & - & 16 \\
\hline 9 & Curvuleria protuberata & 3 & 6 & - \\
\hline \multicolumn{5}{|c|}{ Coelomycetes } \\
\hline 10 & Colletotrichum falcatum & - & - & 4 \\
\hline 11 & $\begin{array}{l}\text { Colletotrichum } \\
\text { gleoporoides }\end{array}$ & - & - & 7 \\
\hline 12 & Phoma sp., & 9 & - & 3 \\
\hline \multicolumn{5}{|c|}{ Sterile form } \\
\hline 13 & Sterile form(black) & 1 & - & - \\
\hline 14 & $\begin{array}{l}\text { sterile form (white } \\
\text { spongy) }\end{array}$ & - & 6 & 2 \\
\hline 15 & sterile form(grey white) & 10 & 7 & - \\
\hline
\end{tabular}

Colonization frequency of sporulating and sterile forms of endophytes isolated from all the organs of Mukia maderasapatana $(L)$ M. Roem was determined (Figure 4). However, the overall colonization frequencies differed with different organs. The number of species occurring in the stem, root and the leaf vary in each segment. The root segment was more densely colonized by the endophytic fungi as evidenced by the total $\mathrm{CF} \%$ which was found to be 86,64 and $92 \%$ for leaf, stem, root respectively. Similar results were obtained in $F$. benghalensis. $^{?}$

Relative percentage of occurrence (RPO) of endophytic fungi isolated from Mukia maderasapatana (L) $M$. Roem

Relative percentage occurrence of endophytes in various segments of Mukia maderasapatana (L) M. Roem is given in (Figure 5). Leaves were dominated by Hyphomycetes $(57 \%)$ followed by Sterile form (29\%), Coelomocytes (14\%) and Ascomycetes were found nil. Stem was dominated by Hyphomycetes (62\%), sterile forms (25\%) and Ascomycetes (13\%) Coelomycetes were found nil. Similarly in root segment Coelomycetes was dominant $(37 \%)$ followed by Hyphomycetes and Ascomycetes of (25\%) and sterile form (13\%).

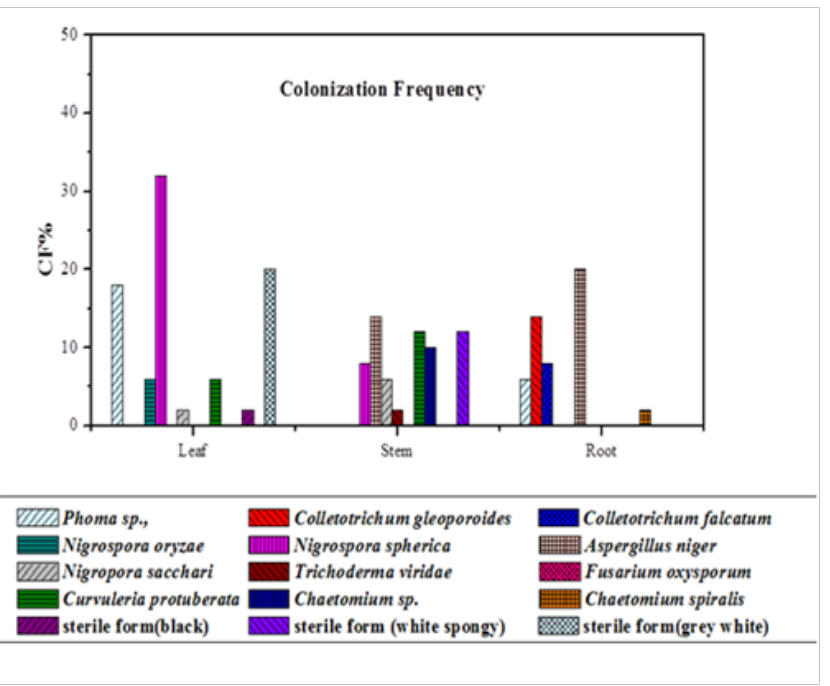

Figure $4 \mathrm{CF} \%$ of Endophytic fungi in different segment of plant.

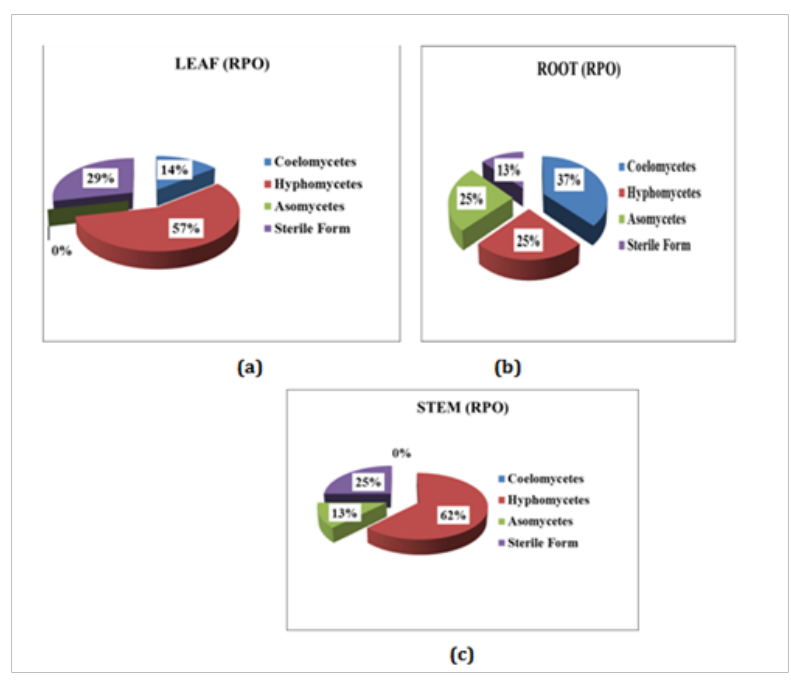

Figure 5 Relative percentage of occurrence of endophytes in different segment of the plant (a) Leaf; (b) Root; (c) Stem.

Endophytic infection rate (EIR \%) of of endophytic fungi isolated from Mukia maderasapatana (L) $M$. Roem

Endophytic Infection Rate of Mukia maderasapatana $(L)$ M. Roem in each segment of leaf, stem and root was found to be 86,78 and $100 \%$ respectively (Figure 6A \& 6B). It revealed that EIR was higher in root segment. Kannan et al., ${ }^{8}$ reported the EIR of different flowers which revealed that EIR were high in Chrysanthemum indica $(81.66 \%)$, followed by Nerium oleifera (61.66\%), Rosa canina (53.33\%), Lilium longiferum (48.33\%) and Plumeria rubra $(8.33 \%)$.

\section{Jaccard's similarity co-efficient}

The comparison between the endophytes recovered from the different host parts was computed using a Jaccard coefficient for 
possible pairs of host parts is given in Figure 6. The highest overlap $(\mathrm{J}=0.36)$ was observed for the fungal communities from leaves and stem, followed by root and stem $(\mathrm{J}=0.28)$ indicating that the close proximity of tissue parts could share common fungi. The similarity between the endophytic assemblages of root and leaf was quite low $(\mathrm{JI}=0.06)$. Similar results were reported by Kumar and Hyde in 2004 in which they reported the comparison between the mycota recovered from the different host parts. The highest overlap ( $\mathrm{JI}=0.147)$ was observed for the fungal communities from leaves and flowers, followed by twig bark and twig xylem $(\mathrm{JI}=0.128)$ indicating that the close proximity of tissue parts could share common fungi. The similarity between the endophytic assemblages of other parts of the host was quite low ( $\mathrm{JI}=0.028$ to 0.079$)$.

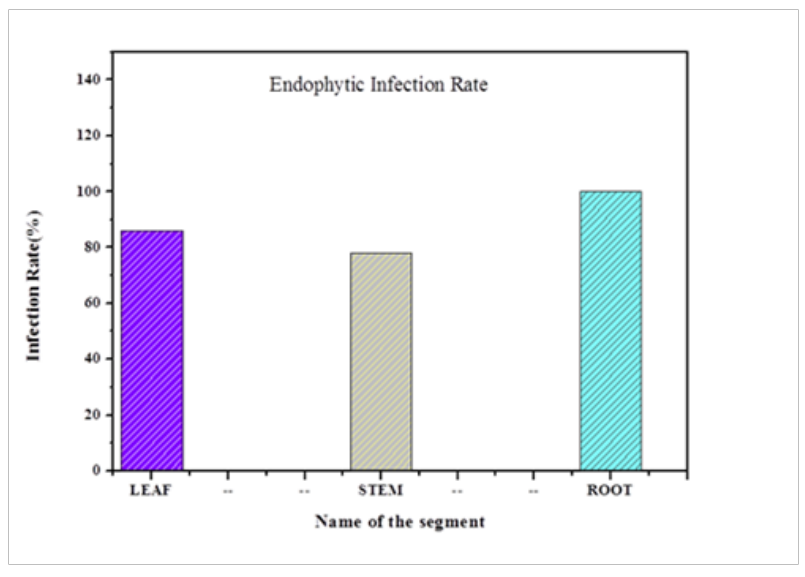

Figure 6A Endophytic infection rate in different segments of plant.

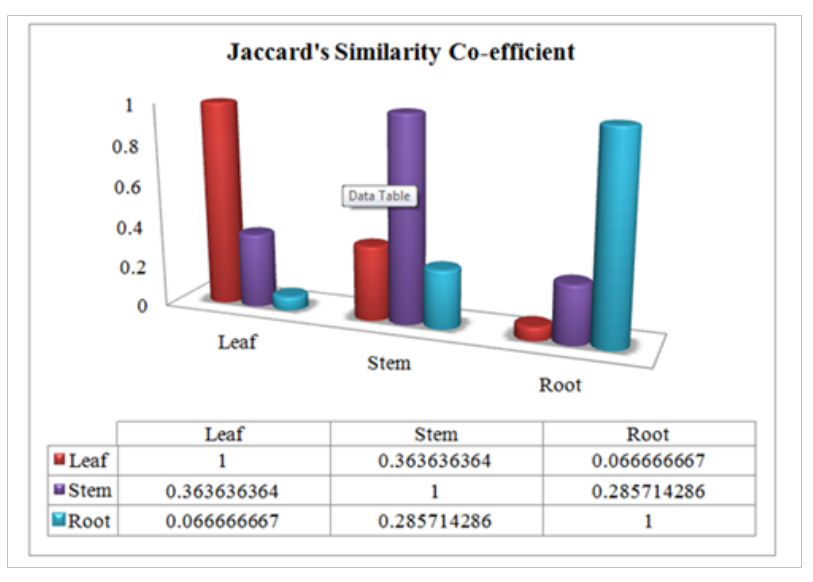

Figure 6B S Jaccard's similarity co-efficient.

\section{Biodiversity indices}

The diversity indices of the endophytic fungal communities from the various parts of the host are given in Figure 7. The Shannon evenness (HS) of endophytes from the leaf, stem and root was found as $0.32734,0.25993$ and 0.20206 . The Shannon index was 0.16822 , 0.13358 and 0.09717 and Gleason index was 1.595236, 1.731234 and 1.789356 for leaf, stem and root. Evenness values for other tissues varied mainly due to the unequal distribution of the Gleason index and Shannon index values. Relative indices for Shannon were 0.04, 0.03 and 0.02 whereas Gleason was $0.14,0.19$ for leaf, stem and root respectively. Similar results were obtained by Kumar and Hyde in 2004.

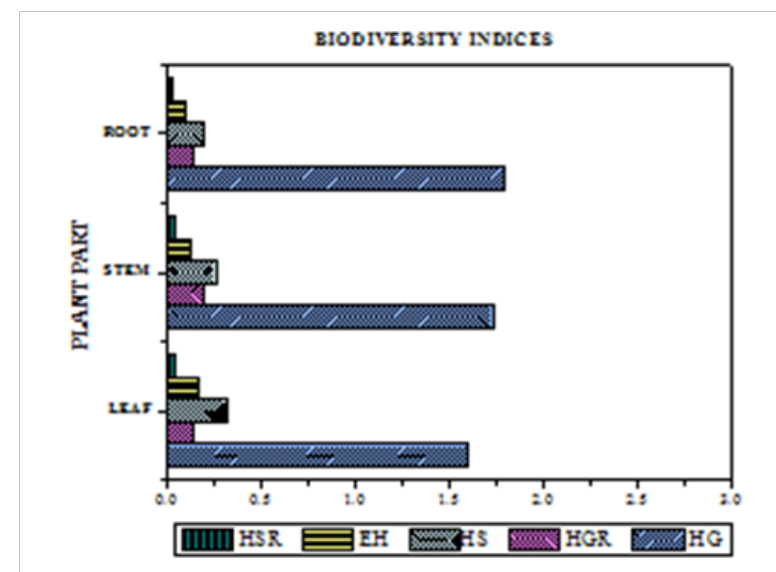

Figure 7 Biodiversity indices for the medicinal plant.

In this study, the endophytic fungi were isolated from the medicinal plant Mukia maderasapatana (L) M. Roem, collected from Sathyamangalam region, Erode district. From 150 segments of leaf, stem and root, totally 132 fungal isolates were obtained which belonged to 9 genera and 12 species. Among these fungal isolates, there were 3 non-sporulating species which was classified as sterile morphospecies. Statistical analysis such as colonization frequency, Relative percentage of occurrence, biodiversity indices, and Jaccard's similarity co-efficient and Endophytic infection rate was done for determining biodiversity of endophytes in this plant. The root segment was more densely colonized by the endophytes as evidenced by the total $\mathrm{CF} \%$ which was found to be 86,64 and $92 \%$ for leaf, stem, root respectively. Relative percentage of occurrence of endophytes in various segments indicated that the Hyphomycetes were dominant. According to Jaccard's similarity co-efficient higher similarity was found between leaf and stem with a value of $0.36 .{ }^{10,11}$ The Shannon evenness (HS) of endophytes from the leaf, stem and root was found as $0.32734,0.25993$ and 0.20206 . The Shannon index was 0.16822 , 0.13358 and 0.09717 and Gleason index was $1.595236,1.731234$ and 1.789356 for leaf, stem and root. Relative indices for Shannon were $0.04,0.03$ and 0.02 whereas Gleason was $0.14,0.19$ for leaf, stem and root respectively.

\section{Acknowledgements}

None.

\section{Conflict of interest}

The author declares no conflict of interest

\section{References}

1. Bezerra JD, Nascimento CC, Barbosa Rdo N, et al. Endophytic fungi from medicinal plant Bauhinia forficata: Diversity and biotechnological potential. Braz J Microbiol. 2015;46(1):49-57.

2. Kamala M, Jayanti T, Sneh G. Microbial pigments: A review. International Journal of Microbial Resource Technology. 2012;14:36 -365.

3. Kumar A, Vishwakarma HS, Singh J, et al. Microbial pigments: production and their applications in various industries. International Journal of Pharmarceutical, Chemical and Biological Sciences. 2015;5(1):203-212. 
4. Schulz B, Wanke U, Draeger S, et al. Endophytes from herbaceous plants and shrubs: effectiveness of surface sterilization methods. Mycological research. 1993;97:1447-1450.

5. Fisher PJ, Petrini O, Sutton BC. A comparative study of fungal endophytes in leaves xylem and bark of Eucalyptus nitens in Australia and England. Sydowia. 1993;45:338-345.

6. Sutton BC. The coelomycetes. fungi imperfecti with pycnidia, acervuli and stromata. CMI, Kew; 1980. p. 1-696.

7. Suryanarayanan TS, Vijaykrishna D. Fungal endophytes of aerial roots of Ficus benghalensis. Fungal Diversity. 2001;8:155-161.
8. Kannan KP, Madhan kumar D, Prakash NU, et al. Fungal endophytes: a preliminary report from marketed flowers. International Journal of Applied Biology. 2011;2:14-18.

9. Kumar DSS, Hyde KD. Biodiversity and tissue-recurrence of endophytic fungi in Tripterygium wilfordii. Fungal Diversity. 2004;17:69-90.

10. Ellis MB. Dematiaceous Hyphomycetes. UK: Commonwealth Mycological Institute; 1971.

11. Ganimede CMA, Schulz M, Tabaglio V. Investigation of endophytic fung associated to Abutilon theophrasti root. Spain: $7^{\text {th }}$ World Congress on Allelopathy, Universida de Vigo; 2014. p. 113-113. 